https://doi.org/10.37208/tgn27319

\section{Edwardsiana alnicola (Hemiptera: Cicadellidae): a leaf-hopper new to Scotland, in Glasgow Botanic Gardens}

\author{
R.B. Weddle \\ 89 Novar Drive, Glasgow G12 9SS \\ E-mail: richard@canto.plus.com
}

In another article on the fauna of Glasgow Botanic Gardens, Scotland I mention the "other insects" that are attracted to the moth trap I run, with the help of the staff at the Gardens, at the west end of the Long Pit glasshouse (Weddle, 2021). These insects are generally within the size range of the majority of the moths, i.e. ca. $5-90 \mathrm{~mm}$ in length or wing-span. However, particularly in the late summer, in the base of the trap there is typically a mass of very small, dead or moribund insects and other invertebrates, which were previously ignored. Recent examination of this material under a dissecting microscope revealed a number of interesting species, including some micro-moths that would otherwise have been overlooked. Many of these species are listed and commented on in Weddle (2021).

One of these small insects was a yellowish leafhopper, about $4 \mathrm{~mm}$ in length, which proved to be a species new to Scotland and not commonly recorded in the rest of the U.K. It was identified by Joe Botting as a male Edwardsiana alnicola (Edwards, 1924) an example of which from Austria is shown in Fig. 1.

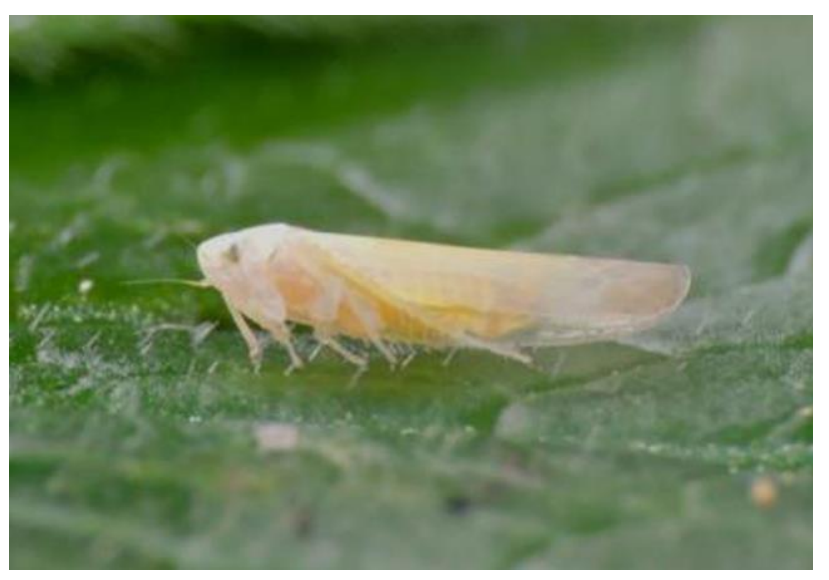

Fig. 1. Edwardsiana alnicola (male); length $c a .4 \mathrm{~mm}$. Pongau district of Salzburg, Austria. (Photo: Betty van Middelkoop)
The individual was collected at NS56796755 on 12th August 2020. The previous most northerly record of this species is to the south of Selby in Yorkshire, England as indicated on the map shown at the Auchenorrhyncha Recording Scheme (2021), which shows rather few records, sparsely distributed over England and Wales south of Yorkshire. It is not clear if this sparseness necessarily indicates rarity, as leafhopper species whose identification requires dissection and very detailed scrutiny of minute features of the aedeagus (intromittent organ) tend to have very low counts of records (A.J.A. Stewart, pers. comm.).

The Glasgow Museums Biological Records Centre database contains no records of E. alnicola, though it does have records of five other Edwardsiana species, all from the late 19th century. These do not appear on the distribution maps at the Auchenorrhyncha Recording Scheme (2021), as these records have still to be shared with the Scheme.

As its specific name implies, E. alnicola feeds on alder (Alnus spp.) leaves. There are several alders in the Gardens; one of these is a large Italian alder (A. cordata) behind the Euing Range of glasshouses, and within $100 \mathrm{~m}$ of the moth trap.

I am grateful to Joe Botting for agreeing to identify the batch of cicadellids containing this species, and to him and Alan Stewart, the organiser of the U.K. Auchenorrhyncha Recording Scheme (2021), for helpful comments.

\section{REFERENCES}

Auchenorrhyncha Recording Scheme (2021). http://www.ledra.co.uk/maps.html Accessed 4th February 2021.

Weddle, R.B. (2021). Further insects and other invertebrates in Glasgow Botanic Gardens, Scotland. The Glasgow Naturalist 27(3), 86-91. http://doi.org/10.37208/tgn27321 